\title{
The Campus as a Living Laboratory: Post-Occupancy Evaluation and a Digital Repository as a Teaching Tool
}

Buildings and landscapes reflect a hidden curriculum that powerfully impacts the learning process. ${ }^{1}$

-David Orr

\section{MARGOT MCDONALD \\ California Polytechnic State \\ University}

\section{STACEY WHITE}

Mode Associates

\section{CLARE OLSEN}

California Polytechnic State University

\section{JEFF LANDRETH}

TK1SC

\section{KATIE WORDEN}

California Polytechnic State

University

\section{LISA HAYDEN}

California Polytechnic State

University

\section{TED HYMAN}

ZGF Architects, LLP
In 2013-14, the California State University system funded 23 grants on 14 campuses in an effort to spur innovation in sustainability. The funding for these grants came from leveraging $\$ 250,000$ of system-wide resources slated for energy efficiency improvements towards the support of educational initiatives that bridged facilities and the academy ${ }^{2}$. The intent of this initiative was to inspire applied research that tied teaching and learning to campus buildings, landscapes, and infrastructure in ways that would inform future project investments related to cost and energy savings as well as sustainability practices and increase the understanding of facility performance while utilizing high-impact educational practices ${ }^{3}$.

Cal Poly, San Luis Obispo developed two winning grant proposals under this program. The first focused on a faculty-led/student-run/industry-funded design-build research project for the installation and operations of a radiant cooling system into an existing teaching space. The second focused on a course redesign to incorporate undergraduate discovery-based research into the Bachelor of Architecture (B.Arch.) curriculum. This involved taking existing laboratory exercises in a required 2 nd-year building science course in order to perform a focused post-occupancy evaluation (POE) for a recently completed LEED Gold certified science building known as the Warren J. Baker Center for Science (Baker Center). The 189,000 square foot building that served as the pilot for this study is located at the heart of the Cal Poly, San Luis Obispo campus, and was designed by the Los Angeles office of ZGF Architects LLP. It is comprised of faculty offices, wet and dry lab spaces, studio classrooms, and lecture halls. It has a long east-west orientation with the majority of the fenestration on the south facade, and a large daylit atrium space at the center with offices and labs at the perimeter of the two wings.

The specific high-impact educational practices employed in the course redesign were: collaborative assignments, field-based experiential and service learning, and active involvement in systematic investigation related to important building performance research questions. In addition, the project scope included development of a digital data repository or data warehouse that would facilitate future interdisciplinary work, not only by architecture, but for K-12, community college, and other university-level STEM/STEAM ${ }^{4}$ disciplines. 


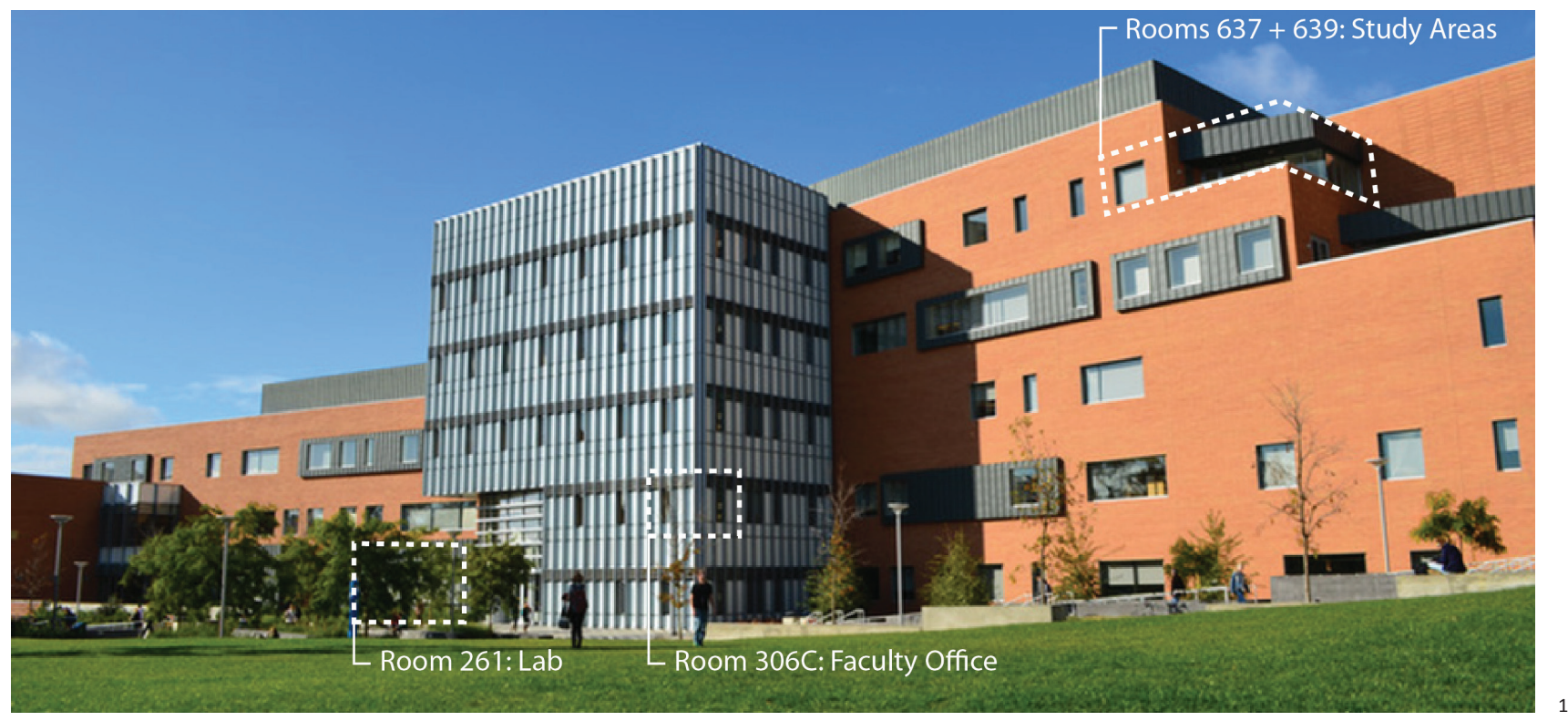

\section{COLLABORATIVE ASSIGNMENTS}

In the pilot study, students were asked to evaluate a specific aspect of building performance working in small teams of two to three persons. In these groups, they learned how to conduct a quantitative and qualitative assessment of the building shading design strategies used on the Baker Center for Science (Figure 1) and were asked to prepare recommendations for improvements based on their findings.

Using site plans, floor plans, elevations, and sections from the construction drawings (PDF's) on file at facilities planning, students were able to construct base drawings before going into the field with handheld instruments including measuring tapes, clipboards, smart phones/digital cameras, and light meters. The lab classes met four hours per week in the studio classroom, or in the field at the Baker Center for Science, with a total of 18-20 students per class. This was a supplement to the large lecture course for the 120 students that met 2 hours per week. Both settings allowed for group discussion and group work as well as instruction on relevant topics such as understanding solar geometry, reading sun path diagrams, interpreting climate data, calculating the overheated period, measuring vertical and horizontal shading angles for existing shading devices, and evaluating quantitative and qualitative aspects of sunlight entering windows adjacent to the study area (Figures 2, 3). Student teams self-selected fenestration and particular orientations on the building that they deemed most relevant to their own concurrent studio projects to study for this assignment. Results were presented in students' studio sections and discussed for opportunities and trade-offs so that they could later be further synthesized into reporting back to the design team.

In the lecture course, students were supplied supplemental background information about the project vision and goals based on a preliminary feasibility study and programming document. Because one instructor for the course had been the campus liaison architect when the study was prepared, students learned about the human dimension of the project's design process which involved capturing the client's aspirations, describing the functional and space needs of future building occupants, and grasping the basis of design established by the California State University system and carried out by the architecture, engineering, and construction team consisting of ZGF Architects LLP, Rumsey Engineering, Gilbane, and a host of consultants and subcontractors.
Figure 1: Study areas outlined on south facade (photo credit: Brittany App) 

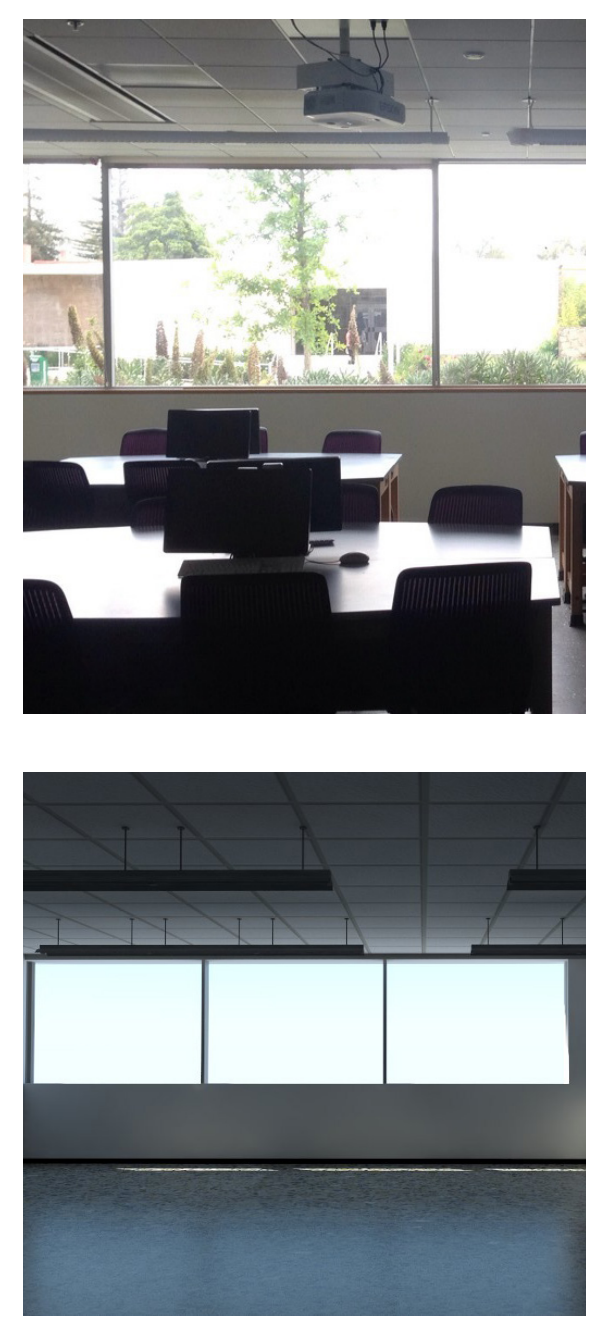

Figure 2: June 10th - 9am, As-Built Room 261 (Photo credit: Stacey White) Figure 3: June 10th - 9am, V-ray Model Comparison Room 261 (Image Credit: Clare Olsen)

\section{IN-THE-FIELD EXPERIENTIAL AND SERVICE LEARNING}

The building science course redesign also afforded opportunities for enhanced field studies leading to direct observation, measurement, and verification of building performance typical of a post-occupancy evaluation, and for interaction with the campus as a form of service learning.

By carefully selecting an on campus case study project as the focal point and then weaving various building-related content throughout the course, students were able to more readily understand both synergistic opportunities of whole building design, such as massing, orientation, shading and trade-offs with daylighting, heat rejection and contextual response. The opportunity to critically assess performance in an objective and systematic manner through instruction, while receiving design team perspectives through separately conducted interviews and anecdotal feedback from building occupants, proved invaluable. This was validated through student's self-reflections and feedback on the teaching and learning approach provided weekly via online forums indicating that overall they felt more comfortable integrating solutions within their own studio work in those topic areas evaluated in the POE.

\section{DISCOVERY-BASED UNDERGRADUATE RESEARCH}

From a NAAB student performance criteria and learning outcomes based perspective, this type of post-occupancy evaluation provides an opportunity for students to demonstrate investigative skills described in Realm A: Critical Thinking and Representation (A.3 Investigative Skills), Realm B: Building Practices, Technical Skills and Knowledge (e.g., B.6 Environmental Systems; B.7 Building Envelope Systems and Assemblies; B.8 Building Materials and Assemblies; and, B.10 Financial Considerations), and Realm C. Integrated Architectural Solutions (namely, C.2 Integrated Evaluations and Decision Making Design Process) by providing reinforcement for topics typically introduced in other coursework such as technical documentation, value engineering and other life-cycle cost related issues.

Using buildings as an investigative teaching and research tool is a longstanding if not widespread pedagogical tradition in architectural education ${ }^{5}$ but one that can be challenging to implement due to limited contact hours for lecture or seminar classes, insufficient practice with or knowledge of post-occupancy evaluation methodologies, a lack of familiarity with or insufficient quantity of measuring equipment, and problems accessing real building data.

There have been several successful programs that aided in the development of investigative hands-on building science education for architects that have the potential for wider application and implementation across disciplines. These include The Vital Signs Curriculum Materials Project ${ }^{6}$ funded through the Energy Foundation, Pacific, Gas \& Electric, and the National Science Foundation in the 1990's and Agents of Change ${ }^{7}$ funded through FIPSE in the early 2000's. Both were instrumental in cultivating a robust learning community of faculty, students, and practitioners who continue to share best practices and teaching resources for over 25 years. Moreover, both efforts contributed to the idea of developing of a digital resource library consisting of case studies, an image archive, curriculum materials, and more.

\section{BUILDING A DIGITAL REPOSITORY}

Generally speaking, data collected (or generated) during most architectural student projects is considered for one time use and then discarded only to collect the same data again the next time the same site is chosen. In order to create a more permanent and lasting record we envisioned that this pilot study could serve as a launch pad of instructional resources for architecture, landscape architecture, engineering, and other disciplines at a variety of instructional levels and at different institutions. As such, the idea of a digital data repository or data warehouse was born. 
Building documentation that has been gathered for this pilot study provides an excellent starting point for the digital repository with the Baker Center for Science at the core. Data and documents have been drawn from all phases of the design/construction process including pre-design, design development, construction documents, and post-occupancy. A wide range of data types are represented such as the Building Information Model (BIM), Excel spreadsheets, eQuest energy models, LEED documentation, and field notes as Portable Digital Format documents (PDF's) as well as images saved as JPEG, TIFF, and GIF files. In addition, a team of instructional faculty and student assistants did their own pre-building investigations to explore potential application of digital analysis tools for representation (Revit), visualization (V-ray), and predictive vs. actual energy modeling (eQuest).

For the purpose of short-term document sharing during development and implementation of the spring course, students and faculty utilized a commercially available dropbox-style shared drive and a secure Learning Management System (LMS) for temporary digital storage of documents and data. The shared drive provided ease of file-sharing between on and off campus users (for example, faculty with architectural firms and consultants). For students, faculty and facilities staff, the LMS course shell provided secure in-house storage and retrieval capability of source documents and also served as a location for students to upload their completed assignments.

For more permanent storage, access, and public document sharing, other web collectionbased tools are being evaluated for adoption such as Artstor's Shared Shelf or Omeka, a web-based, web publishing platform for collection-based research for scholarly, library, and museum work managed through common indexing standards. Other alternatives for managing archived data include Zotero, a bibliographic tool that allows for either remote (web) or local desktop access to reference files through an indexing system. The campus also provides a web-based portal called the Digital Commons for sharing of campus-authored or affiliated documents.

The utility of any of the building data and documents depends significantly on capturing a detailed description of the source documents to include their origin, authorship, date, version-control, and file formats. These attributes of the data records are referred to as metadata or "a set of data that describes or gives information about other data" ${ }^{8}$ and are key factors affecting the user ability to interpret retrievable digital files in a meaningful manner.

\section{CHALLENGES OF WORKING WITH REAL CAMPUS BUILDINGS}

While the pilot study provided excellent opportunities to launch building investigations for faculty and students, it was not without its trials and tribulations. For example, it took the instructional team over one year to receive building energy data files from facilities services. In addition, some data is password protected and can only be made available to students on a limited duration. Field work conducted in snapshots may lead students to incorrect conclusions about building performance and needs to be carefully judged. Assignments archived with uncorrected information may be misinterpreted at a later date. The list goes on. All of these items will be taken into consideration as the project is evaluated for future iterations.

From the design side, willingness to open facilities to performative assessment can be challenging, as some firms may consider critical assessment exposure to avoid. However, we found that the project team -- architects, engineers and consultants as well as the campus management and leadership personnel, were willing participants. In particular, ZGF's culture of reporting and self-assessment as well as improvement is both understandably rare and was critical to project success. 


\section{CONCLUSION}

The objective of this pilot study was to redesign existing coursework in ways that would engage students and faculty in the investigation of environmental performance "in their own backyard." Our team tapped the potential of post-occupancy evaluation methods in order to activate high impact educational practices (such as collaborative assignments, experiential and service learning in the field, and discovery-based undergraduate research). At the same time, the pilot created an opportunity to facilitate further teaching and research opportunities on campus through the development of a digital data repository or data warehouse. The warehouse will be built upon the various data and documents related to the whole building life-cycle (from pre-design through occupancy), and will include the results of academic research and field studies as new data types thereby perpetuating the teaching and learning cycle.

The project illustrates the potential benefits of using campus buildings (and sites) to improve student learning through engagement, ignite new collaborations for faculty interdisciplinary research and teaching, and strengthen the connection between facilities and the academy while promoting environmental change.

\section{NEXT STEPS}

Within the realm of high impact educational practices, there are many more dimensions to student learning that can be explored through the Campus as a Living Lab initiative in general and the Baker Center for Science in particular. This includes enhancements and refinements to those attempted, and new areas ripe for development that relate to student and faculty forays into building and site performance research. In total, the range spans from community service learning, curriculum development university-wide including STEM/STEAM disciplines, first year seminars, writing intensive courses, collaborative assignments, diversity learning, and capstone projects in the future.

We look forward to completing future investigations focusing on assessment of student learning outcomes; investigating additional building science topics such as thermal comfort, mechanical systems, acoustics, and water use; and, exploring the boundaries of collaboration between architecture and engineering, art and materials science, chemistry and horticulture, and so on, to bring together the diverse epistemologies and academic disciplines with the Baker Center serving as a hub. In the words of Clare Olsen and Sinéad MacNamara, "Creative moments occur when making connections across boundaries, what's commonly referred to as 'thinking outside the [disciplinary] box.' Conversations with others outside one's discipline, approaching problems from a new perspective, and the propensity to fuel game-changing, insightful, exhilarating revelations. ${ }^{\prime 9}$ What better educational setting than the campus as the living laboratory as a stage for collaborative learning and discovery-based research that builds upon one's direct experience in the built environment.

4. Rhode Island School of Design, "STEM to STEAM," accessed May 1, 2015, http: /stemtosteam.org.

5. Leibowitz, Sandra (2005). Ecological Design and Building Schools. Oakland, CA: New Village Press.

6. Oxford Dictionaries, accessed June 1, 2015, http: / www.oxforddictionaries.com/us/definition/american_english/metadata .

7. Center for the Built Environment, University of California, Berkeley, "The Vital Signs Project", last modified September 9, 2002, http: /vitalsigns.ced. berkeley.edu.

8. Alison Kwok, "Agents of Change", copyrighted in 2005, http: /aoc.uoregon.edu.

9. Olsen, Clare and Sinéad MacNamara. (2014). Collaborations in Architecture and Engineering New York: Routledge. 